\title{
THE CORACOID IMPINGEMENT SYNDROME
}

\author{
DAVID M. DINES, RUSSELL F. WARREN, ALLAN E. INGLIS, HELENE PAVLOV
}

From The Hospital for Special Surgery and Cornell University Medical College, New York

\begin{abstract}
Coracoid impingement results from encroachment on the coracohumeral space, presenting as anterior shoulder pain and clicking, particularly in forward flexion, medial rotation, and adduction.

In eight shoulders in seven patients, coracohumeral decompression by excision of the lateral $1.5 \mathrm{~cm}$ of the coracoid with re-attachment of the conjoined tendon gave pain relief in all, and complete relief in six. This procedure is described and recommended.
\end{abstract}

Subacromial impingement, initially termed the supraspinatus syndrome by Codman and the impingement syndrome by Neer, results in tendinitis and degeneration of the rotator cuff and is a well-documented cause of pain and disability (Neer 1972, 1983; Hawkins and Kennedy 1980). We report seven patients (eight shoulders) with pain due to encroachment of the lesser tuberosity on the coracoid process. We have termed this the coracoid impingement syndrome'. In these patients, several of whom had failure of previous decompression procedures, pain was relieved by operation on the coracoid process. Gerber, Terrier and Ganz (1985) have recently reported a similar condition, but their series included a high percentage with iatrogenic causes.

\section{PATIENTS AND METHODS}

The seven patients were seen over a period of six years. Four were men, and three were women; their average age was 29.5 years (range 17 to 50 years). The dominant arm was involved in seven of the eight shoulders. We reviewed clinical and operative records, and the radiographs. All had had surgery to correct the coracoid impingement; the average follow-up was three years (range two to 5.5 years).

D. M. Dines, MD, Orthopaedic Surgeon

North Shore-Cornell University Hospital, Manhasset, New York 11030, and The Hospital for Special Surgery, 535 East 70th Street, New York, New York 10021, USA.

R. F. Warren, MD, Orthopaedic Surgeon

A. E. Inglis, MD, Orthopaedic Surgeon

H. Pavlov, MD, Radiologist

The Hospital for Special Surgery, 535 East 70th Street, New York, New York 10021, USA.

Correspondence should be sent to Dr D. M. Dines at the Hospital for Special Surgery.

(C) 1990 British Editorial Society of Bone and Joint Surgery $0301-620 \mathrm{X} / 90 / 2019 \$ 2.00$

J Bone Joint Surg [Br] 1990; 72-B:314-6.
Symptoms. All patients had anterior shoulder pain made worse by forward flexion and medial rotation combined with horizontal adduction. This manoeuvre produced a painful click in seven of the eight shoulders, and in one shoulder, flexion was restricted to $100^{\circ}$. Most of the patients were involved in activities which required an overhead position of the arm in medial rotation: two were tennis players, the one with bilateral symptoms was a weightlifter and one was a carpenter. Five had had previous shoulder surgery.

Clinical findings. All patients had tenderness in the anteromedial shoulder over the coracoid process. In four shoulders this was severe and in seven a painful click could be reproduced by the examiner with forward flexion and medial rotation in varying degrees of horizontal

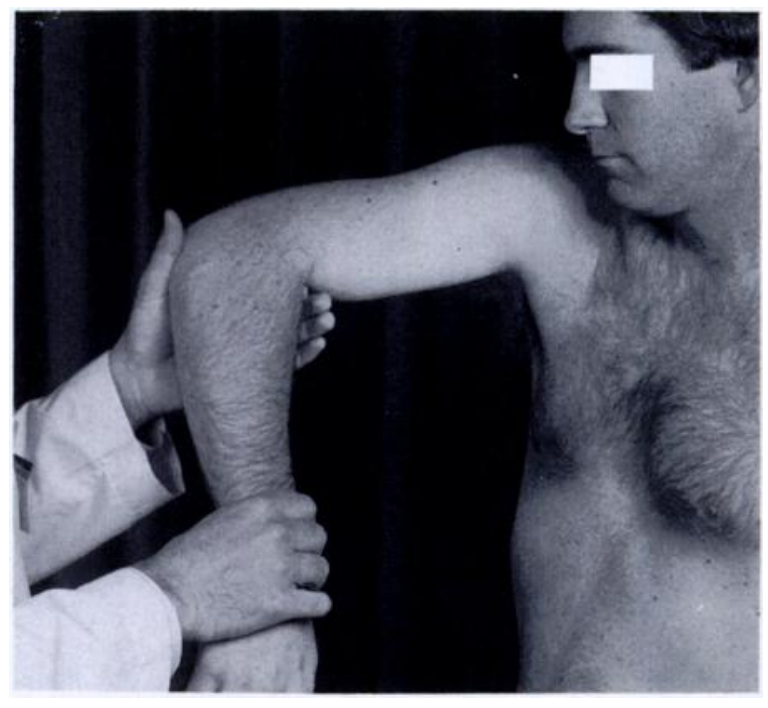

Fig. 1

The coracoid impingement sign. Pain and clicking are elicited by passive flexion and adduction in medial rotation. 
adduction. We have termed this the coracoid impingement test (Fig. 1). Yagerson's test was negative in all patients and none had clinical evidence of a rotator cuff tear or any shoulder instability. Muscle power and neurological function were normal in all patients. Subacromial injection did not improve symptoms, but in every patient an injection of xylocaine between the humeral head and the coracoid process gave marked relief.

Previous operations. Five patients had had one or more surgical procedures, including diagnostic arthroscopy, glenoplasty (Scott 1967), tenodesis of the long head of the biceps (four patients), and acromioplasty (two patients). These patients provided difficult diagnostic problems.
Fig. 2a

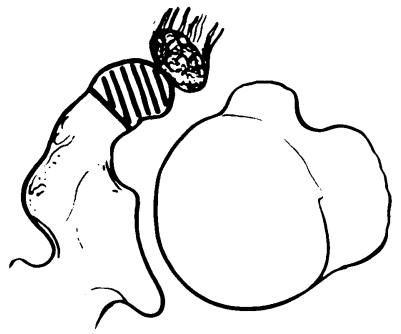

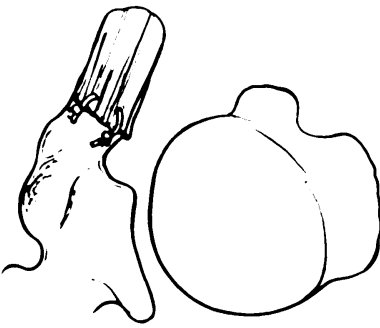

$2 b$
Decompression of the coracohumeral space by excision of the tip of the coracoid.

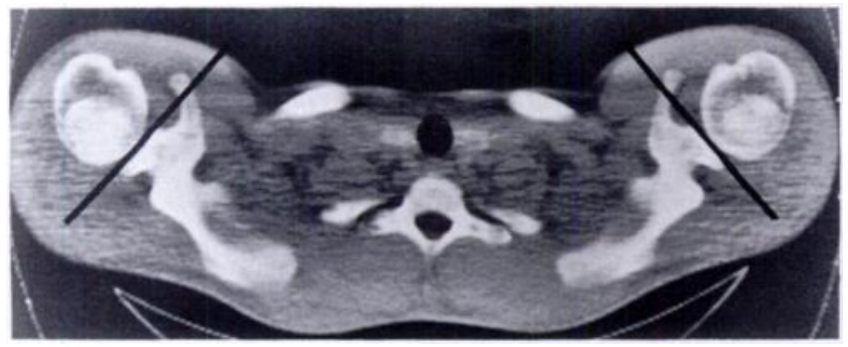

Fig. 3

The coracoid index on a CT scan. The projection of the coracoid beyond the line of the glenoid is measured (see text).

Radiography. Routine radiographs included standard anteroposterior and axillary views, while four patients had bicipital groove views. Four patients had arthrograms pre-operatively. None of these helped with the diagnosis.

Operative techniques. In the first two shoulders, decompression of the coracoid region was achieved by simple osteotomy of the neck of the coracoid process to change its angle by bending it medially. Since the final position was then variable until healing was complete, in later patients we removed either the outer part of the tip of the coracoid (three shoulders) or the outer $1.5 \mathrm{~cm}$ (three shoulders).
After a deltopectoral approach, the conjoined tendon is dissected from the tip of the coracoid and a part of the coraco-acromial ligament, if still present, is excised. After this, either the anterolateral aspect of the tip of the coracoid process or the whole tip is removed to open the coracohumeral space (Fig. 2a), about 1 to $1.5 \mathrm{~cm}$ being removed. The conjoined tendon is then re-attached to the remaining base of the coracoid process (Fig. 2b). We now recommend the more radical excision.

Postoperatively a sling is used for seven to 10 days, with early active and active-assisted exercises. After two to three weeks, active rotation exercises are started but heavy loading of the conjoined tendon is avoided for six weeks.

\section{RESULTS}

In every shoulder, the lesser tuberosity was closely approximated to the coracoid process during forward flexion, medial rotation and adduction. In one case there was a fracture of the lesser tuberosity with bony overgrowth at the medial wall of the bicipital groove, which seemed to be the cause of the encroachment. No rotator cuff tears were seen; the long head of the biceps tendon was normal in the four cases in which it was explored.

Six shoulders had complete resolution of preoperative symptoms and two had mild residual discomfort during stressful activity in the overhead position, but no pain at rest. The coracoid impingement test was negative in six shoulders and only mildly positive in two. At follow-up, all but one shoulder had an almost complete range of movement, the exception showed $30^{\circ}$ restriction of forward flexion compared with the normal side.

Clicking in forward flexion, medial rotation and adduction persisted in only one patient, and all patients were able to return to their original level of activity or occupation.

\section{DISCUSSION}

Coracoid impingement is a rare cause of anterior shoulder pain, which should be considered especially after the failure of previous surgery for impingement, biceps tendon lesions, instability, or an operation on the coracoid such as the Bristow or Trillat procedures (Trillat and Leclerc-Chalvet 1973). There have been previous reports (Goldthwait 1909; Bennett 1941; Dines, Warren and Inglis 1982), as well as that of Gerber et al (1985) on patients who had undergone the Trillat procedure.

The potential space between the coracoid process and the anterior humerus could be reduced by any changes in the structures around it. In our series we recorded fracture of the lesser tuberosity, calcification within the subscapularis tendon, abnormal glenoid orientation secondary to a glenoid osteotomy, and simple prominence of the coracoid. Other possible causes are 
displaced fractures of, or operations on, the coracoid or for transfer of the long tendon of biceps (Froimson 1978; Jobe, personal communication 1986).

We have attempted to evaluate the coracoid by CT scans and have measured the 'coracoid index' in 67 normal shoulders (Fig. 3). The average value was $8.2 \mathrm{~mm}$ (range -2.5 to $+25 \mathrm{~mm}$ ). Only one of our patients had a CT before operation: the index was $23.5 \mathrm{~mm}$. Any variation in length or angulation may have a role in this syndrome and we are continuing to study this aspect of the condition.

Conclusion. The coracoid impingement syndrome is an uncommon cause of anterior shoulder pain. Axillary radiographs and CT scans may help evaluation of the lesser tuberosity and the coracoid especially after previous shoulder operations. Temporary improvement after infiltration of local anaesthetic confirms the diagnosis; decompression by excision of the lateral $1.5 \mathrm{~cm}$ of the coracoid is the recommended treatment for persistent cases.

No benefits in any form have been received or will be received from a commercial party related directly or indirectly to the subject of this article.

\section{REFERENCES}

Bennett GE. Shoulder and elbow lesions of professional baseball pitcher. JAMA 1941 ; 117:510-4.

Dines D, Warren RF, Inglis AE. Surgical treatment of lesions of the long head of the biceps. Clin Orthop 1982; 164:165-71.

Froimson AI. Fracture of coracoid process of the scapula. $J$ Bone Joint Surg $[\mathrm{Am}] 1978 ; 60-\mathrm{A}: 710-1$

Gerber C, Terrier F, Ganz R. The role of the coracoid process in the chronic impingement syndrome. J Bone Joint Surg [Br] 1985; 67 B: 703-8.

Goldthwait JE. An anatomic and mechanical study of the shoulderjoint, explaining painful shoulder, recurrent dislocations and brachial neuralgias or neuritis. Am J Orth Surg 1909; 6:579-606.
Hawkins RJ, Kennedy JC. Impingement syndrome in athletes. Am J Sports Med 1980; 8:151-8.

Neer CS II. Anterior acromioplasty for the chronic impingement syndrome in the shoulder: a preliminary report. J Bone Joint Surg [Am] 1972; 54-A :41-50.

Neer CS II. Impingement lesions. Clin Orthop 1983; 173:70-7.

Scott DJ Jr. Treatment of recurrent posterior dislocations of the shoulder by glenoplasty: report of three cases. J Bone Joint Surg [Am] 1967; 49-A:471-6.

Trillat A, Leclerc-Chalvet F. Luxation récidivante de l'épaule. Paris: Masson et Cie, 1973. 